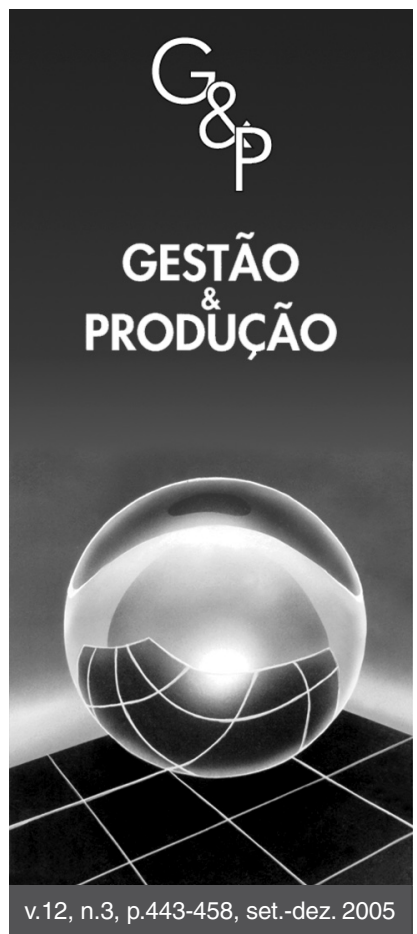

\title{
MEDIÇÃO E PRÉ-CONTROLE DO DESEMPENHO DE UM PLANO DE AÇÕES ESTRATÉGICAS EM MANUFATURA
}

\author{
Miguel Afonso Sellitto \\ Programa de Pós-Graduação em Engenharia de Produção e Sistemas, \\ Universidade do Vale do Rio dos Sinos, UNISINOS, \\ Av. Unisinos, 950, CEP 93022-000, São Leopoldo, RS, Brasil, \\ e-mail: sellitto@unisinos.br \\ Cláudio Walter \\ Programa de Pós-Graduação em Engenharia de Produção, \\ Universidade Federal do Rio Grande do Sul, UFRGS, \\ Praça Argentina, 9, CEP 90040-020, Porto Alegre, RS, Brasil, \\ e-mail: maxiprod@pro.via-rs.com.br
}

Resumo

Recebido em 30/6/2005

Aceito em 30/11/2005

O objetivo deste trabalho é apresentar um método para a medição e o pré-controle de um plano de ações estratégicas em manufatura. Uma premissa de pesquisa é que o método possa modificar as medições com a mesma rapidez com que o ambiente competitivo se modifica, permitindo que a execução do plano estratégico se mantenha alinhada com os objetivos estratégicos de manufatura. Para testar e refinar o método, foi desenvolvido um estudo de caso em uma manufatura de ferramentas mecânicas. Foi recuperada a estratégia incremental de manufatura, composta por seis objetivos e um plano formado por quinze cursos de ação, e aplicado um método multicriterial para a definição de indicadores e de sua importância relativa. Partindo do desempenho atual medido pelos indicadores, o método mensura o potencial de cada ação em contribuir para o atingimento dos objetivos. Segue-se uma avaliação das lacunas entre o objetivo de desempenho, o desempenho atual e o desempenho esperado das ações. Avalia-se finalmente, em função dos potenciais de melhoria de desempenho de cada ação e das restrições de investimento, a priorização das ações. Resultam possibilidades de alterações na estratégia, que aumentam o valor pré-alimentado de desempenho, caracterizando a ação de pré-controle da estratégia. Uma parte dos resultados foi discutida, chegando-se a alternativas de continuidade.

Palavras-chave: medição de desempenho em manufatura, controle de estratégia em manufatura, estratégia em manufatura.

\section{Introdução}

A gestão da manufatura inclui a medição e o controle do desempenho das ações derivadas da estratégia de operação. Se a medição de desempenho não representar os objetivos da estratégia, estes podem não ser atingidos, pois é por esta medição que se comparam os objetivos com os resultados alcançados pelas ações estratégicas.

Segundo Martins (1998), o interesse pela medição de desempenho de estratégias se intensificou a partir dos anos 1990, principalmente pela insatisfação com métodos de avaliação baseados em resultados financeiros. Para Kennerly e Neely (2003), a competição atual tem exigido, além dos resultados financeiros, responsividade em outros fatores, tais como a qualidade, a velocidade nas entregas, a confiabilidade nos prazos e a flexibilidade em serviços. A medição destes fatores é multidimensional e requer variáveis intermediárias, agregando e combinando diversas variáveis antecipatórias, que indiquem a tendência e antecipem as ações corretivas requeridas para a obtenção dos resultados finais.

Estruturas como o Balanced Scorecard (BSC) e o prêmio Malcolm Baldridge usam medições multidimensionais e intermediárias, originadas da combinação de múltiplas variáveis. Para Evans (2004), estas são as mais influentes estruturas de medição de desempenho no cenário atual. $\mathrm{O}$ estudo de estruturas multivariadas pode se valer do campo da decisão multicriterial. 
Bourne et al. (2000), Bititci et al. (2002), Gomes et al. (2004) e Melnick et al. (2004) apresentam resenhas parciais de métodos já propostos para a medição de desempenho. Miranda e Silva (2002) apontam vinte e um modelos publicados após 1990. Teses recentes de doutoramento (Sellitto, 2005; Hansen, 2004; Müller, 2003; Gasparetto, 2003; Martins, 1998) incluem revisões de literatura sobre medições de desempenho.

O objetivo deste artigo é apresentar um método para a medição e o pré-controle de um plano de ações estratégicas em manufatura. A medição deve ser flexível o suficiente para adaptar-se às modificações típicas de ambientes competitivos. Usa-se um método multicriterial de apoio à decisão para obter medições ponderadas e a noção de elo de realimentação de informações, oriunda da cibernética, para o pré-controle. Fala-se em pré-controle, pois o artigo não se estende no tempo, limitando-se ao início do processo de controle, a pré-alimentação das ações de controle. O artigo está organizado em i) introdução; ii) revisão de temas próximos, tais como estratégia, competição e desempenho em manufatura; iii) método e resultados; iv) uso dos resultados; e v) conclusão e continuidade. A revisão de temas de fundo, tais como os enfoques sistêmico e cibernético em manufatura, decisão multicriterial, grupos focados, método AHP e teste de confiabilidade em medições de intangíveis pelo alfa de Crombach, é apresentada em Sellitto (2005).

\section{Estratégia e competição em manufatura}

Uma estratégia empresarial apresenta três níveis: corporativo, de negócios e funcional. A estratégia corporativa relaciona-se com o ambiente em que o grupo empresarial atua e define os negócios a explorar, segundo estratégias de negócios. Os objetivos de negócios, por sua vez, serão atingidos por estratégias funcionais. A relação entre a estratégia de negócios e estratégias funcionais é hierárquica, pois a estratégia de negócios se desdobra e se sustenta em estratégias funcionais, que a recompõem e sintetizam (Paiva et al., 2004).

Para este artigo interessa a estratégia de manufatura. Segundo Skinner (1996), a manufatura coordena e gerencia os esforços de produção de produtos e serviços, ao longo de uma cadeia de atividades que geram valor. A cadeia se inicia no projeto do produto, passa pelo desenvolvimento do processo de fabricação, fornecimento de insumos, fabricação, armazenagem e distribuição, chegando aos serviços associados ao produto. A estratégia de manufatura deve incluir decisões que mantenham entre si mútua coerência e que considerem e cubram todas as atividades da cadeia de valor da manufatura, já citada.

Wheelwrigth (1984) propõe que se formule a estratégia de manufatura por uma seqüência de nove categorias de decisões, que criem uma vantagem competitiva na indústria: i) capacidade de produção; ii) localização, tipologia, volume e ciclo de vida de instalações; iii) equipamentos, layouts e tecnologia de operação; iv) integração vertical e opções do tipo comprar ou fazer; v) recursos humanos; vi) requisitos de qualidade a serem atendidos; vii) escopo de produção e de novos produtos; viii) sistemas de gerenciamento e melhores práticas a seguir; e ix) relações e integração entre as estratégias funcionais.

Hayes e Wheelright (1984) apontam duas classes de estratégias de manufatura: i) a estratégia estrutural, que define aspectos de longo tempo de maturação, tais como a localização industrial e a tecnologia de produção; e ii) a estratégia infra-estrutural, que diz respeito a fatores de menor prazo de maturação, tais como o tipo e o tamanho da força de trabalho, o nível de qualidade e a flexibilidade da produção. Sellitto (2005) chama a primeira de estratégia basal, por formar uma base de longo prazo. A esta base se soma uma estratégia incremental, que integra fatores que se esgotam no curto prazo e requer modificações quase que permanentemente, em uma relação essencialmente dinâmica com o ambiente e operando como acréscimo à base montada. Neste artigo, o plano de ações estratégicas em estudo, composto por quinze cursos de ação individuais, é uma estratégia incremental de manufatura.

\section{Medição e controle de desempenho em manufatura}

Bititci (1995) cita pesquisas que apontam o desdobramento dos objetivos de negócios e a medição de desempenho como passos para criar uma vantagem competitiva na manufatura. Para Neely et al. (1995), indicadores de desempenho devem formar um conjunto estruturado em dimensões. Para White (1996), uma estrutura padronizada de medições garante que não haja medições excessivas e nem falta de medições. Segundo Bititci et al. (2001), sistemas de medição de desempenho baseados exclusivamente em resultados financeiros não são capazes de desdobrar objetivos de negócios em objetivos de manufatura. Conclui-se que, para medir e controlar o desempenho da manufatura, deve-se estruturar os objetivos de competição em uma estrutura de variáveis que possam ser medidas e controladas.

Autores estruturaram objetivos para a competição em manufatura. Slack (1993) aponta a i) qualidade; ii) velocidade; iii) confiabilidade; iv) flexibilidade; e v) custo. Contador (1996) aponta o i) preço; ii) produto; iii) prazo até o uso; iv) assistência e serviços; e v) imagem associada ao produto. Skinner (1976) apud Davis et al. (2001) aponta quatro prioridades competitivas: i) baixo custo; ii) alta qualidade; iii) entrega rápida; e iv) alta flexibilidade. Davis et al. (2001) acrescentam o oferecimento de serviços associados ao uso do produto. Finalmente, Paiva 
et al. (2004) tratam de i) custo; ii) qualidade; iii) flexibilidade; iv) desempenho de entrega; e v) inovatividade como objetivos da manufatura. Segundo Slack (1993), os objetivos de competitividade podem não ter a mesma importância relativa. Acrescenta-se que a importância relativa também pode variar no tempo, em função de modificações tecnológicas e da entrada e saída de atores na competição. Os modelos citados são comparados na Tabela 1.

Os objetivos de competição em manufatura se relacionam com a medição de resultados segundo uma perspectiva sistêmica. A medição pode ser um elo de realimentação de gestores, se estes, ao não atingirem os objetivos mensurados, reagirem e ajustarem seus procedimentos, em ciclos de aprendizagem. Adicionalmente, um sistema de manufatura realimentado por informações pode detectar a tempo as mudanças ambientais que estão afetando os resultados e executar as adaptações necessárias, sob a forma de ações de controle (Wiendahl, 1989).

A ação sistêmica de medição e controle estratégicos pode ser representada como na Figura 1. O símbolo de somatório se refere à comparação entre grandezas. Defi- nidas a visão, a missão, os valores e os objetivos de negócios a desdobrar em estratégias de operação, ao longo da execução mensuram-se os resultados, que passam a ser o elo de realimentação da estratégia e do processo estratégico.

Kaplan e Norton (1997) apontam um duplo circuito de aprendizagem, reconhecível na Figura 1, referindo-se à execução da estratégia e à formulação da estratégia. Bourne et al. (2000) citam duas funções dos sistemas de medição de desempenho, também reconhecíveis na mesma figura: a medição da execução estratégica e a verificação da validade dos pressupostos assumidos na formulação da estratégia. Pode ocorrer que os objetivos de uma estratégia de manufatura tenham sido atingidos, tais como, por exemplo, a redução de custo e o aumento da qualidade, e o objetivo de negócios não tenha sido alcançado, tal como, por exemplo, o aumento do lucro líquido. Tal situação indica falha na formulação da estratégia, pois um pressuposto assumido, tal como a manutenção do preço de venda, pode não ter sido confirmado.

Uma mudança de cenário, tal como a referida, pode ser detectada a tempo por medições intermediárias, podendo originar uma auto-adaptação na estratégia.

Tabela 1. Objetivos comparados de competição em manufatura.

\begin{tabular}{lcccl}
\hline & \multicolumn{2}{c}{ Objetivos de competição segundo: } & Pescrição do objetivo \\
\hline Qualidade & Contador (1996) & Davis et al. (2001) & Paiva et al. (2004) & \\
\hline Velocidade & Produto & Qualidade & Qualidade & $\begin{array}{l}\text { Fornecer produtos e serviços de alta } \\
\text { qualidade. }\end{array}$ \\
\hline Confiabilidade & - & Entrega & - & $\begin{array}{l}\text { Fornecer produtos e serviços com } \\
\text { rapidez. }\end{array}$ \\
\hline Flexibilidade & - & - & Desempenho de entrega & $\begin{array}{l}\text { Cumprir os múltiplos compromissos } \\
\text { de entrega a clientes. }\end{array}$ \\
\hline Custo & Preço & Flexibilidade & Flexibilidade & $\begin{array}{l}\text { Variar rapidamente os compromissos } \\
\text { de manufatura. }\end{array}$ \\
\hline- & Serviços & Custo & Custo & $\begin{array}{l}\text { Fornecer produtos e serviços a baixo } \\
\text { preço. }\end{array}$ \\
\hline- & Serviços & - & $\begin{array}{l}\text { Acompanhar e orientar o uso do } \\
\text { produto. }\end{array}$ \\
\hline- & Imagem & - & $\begin{array}{l}\text { Criar imagem favorável ao uso do } \\
\text { produto no mercado. }\end{array}$ \\
\hline
\end{tabular}

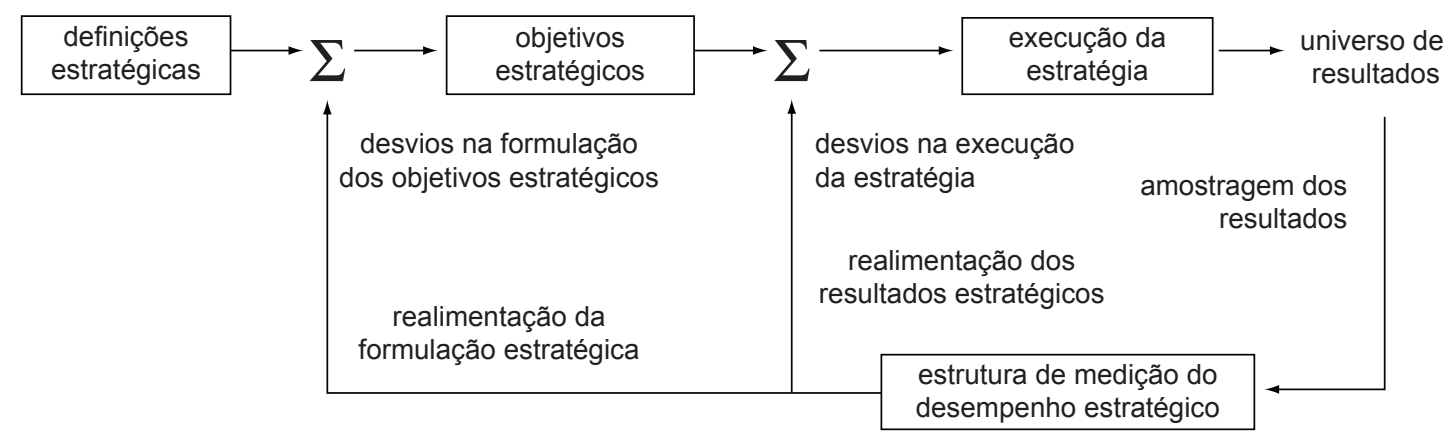

Figura 1. Representação sistêmica para a medição e controle de desempenho. 
A medição de desempenho pode ser pensada como uma estrutura hierárquica de variáveis de estado, com métodos específicos de cálculo. Estruturas genéricas, no entanto, endereçam situações intermediárias: adotado um modelo padronizado de medição, caso o cenário mude, o modelo deixa de ser válido, podendo surgir lacunas entre objetivos e medições.

Pereira e Nagano (2002) inserem a medição de desempenho no processo de gestão estratégica, como na Figura 2. O processo inicia-se pela análise ambiental e passa pela formulação e implementação da estratégia. Ao fim, tem-se a avaliação dos resultados e a sua realimentação e, com base nesta, o controle da execução e eventual reformulação da estratégia.

\section{A pesquisa: objetivos e método}

Pretende-se usar o enfoque de Russell (1977) para o método científico: i) observação, composta de experiência vivencial acumulada, estudos analíticos e referenciais teóricos que organizem os conhecimentos existentes; ii) generalização de regularidades observadas pela formulação de hipóteses; e iii) experimentação das hipóteses em estudos de caso que as refinem e robusteçam e incorporem peculiaridades que escaparam à generalização. Eckstein (1975 apud Roesch, 1999) enumera cinco modos de contribuição de um estudo de caso: i) uma descrição profunda de um objeto para outros estudos; ii) interpretação de regularidades observadas em um objeto; iii) heurístico, em que uma situação é deliberadamente construída para expor relações generalizáveis; iv) sondagens plausíveis acerca de uma teoria proposta pelo modo heurístico; e v) o caso crucial, que apóia ou refuta uma teoria.

O objetivo de pesquisa é propor uma estrutura de medição de desempenho de um plano de ações estratégicas, que será executado em uma manufatura que possui uma estratégia basal definida, de modo a permitir mudanças nas medições, segundo as modificações no ambiente de

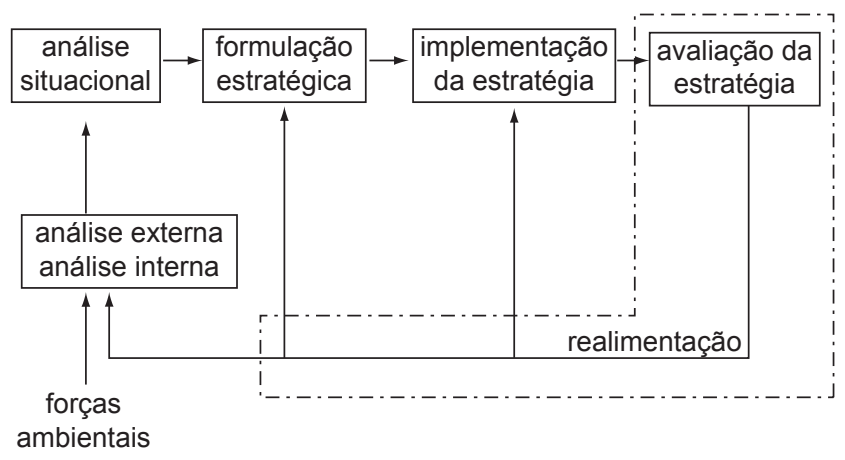

Figura 2. A medição de desempenho e a gestão estratégica (Fonte: adaptado de Pereira e Nagano, 2002). negócios. A técnica de pesquisa é o estudo de caso, do tipo sondagem plausível.

Foi escolhida uma manufatura, pertencente a uma organização multinacional, com planejamento estratégico formal, que projeta e fabrica ferramentas mecânicas. A manufatura é representada por sete processos em série: forjaria, rebarbagem, usinagem, tratamento térmico, montagem, marcação e embalagem e expedição. A forjaria atende a duas linhas em divergência, destinando cerca de $20 \%$ da produção à linha em estudo, conforme a Figura 3.

A empresa formulou uma estratégia incremental de manufatura, o plano estratégico, que consiste de seis objetivos e quinze cursos de ação, que afetam diversos indicadores, sem mútua exclusividade. Como não é objetivo deste trabalho estudar o processo de formulação da estratégia incremental, coloca-se apenas que é um método qualitativo apriorístico que associa a cada curso de ação um único indicador, não articulado com os demais.

É o seguinte o método usado neste trabalho.

- Passo 1: Identificar o plano de ações estratégicas de manufatura. O plano é composto por seis objetivos de manufatura, relacionados às estratégias funcionais de recursos humanos, de mercado, financeiras e operações de manufatura e quinze cursos de ação. São identificados executivos que possam discutir e quantificar os aspectos intrínsecos usados na formulação do plano;

- Passo 2: Definir indicadores e importâncias relativas. Os executivos, em grupo, debatem o plano e identificam os pressupostos admitidos para atingir os objetivos, associando a cada passo da rota estratégica uma grandeza intangível e uma variável manifesta, chegando a uma estrutura hierárquica de três níveis, o objetivo global de manufatura, os objetivos estratégicos e os indicadores. Os executivos ponderam a estrutura pelo método AHP e testam a confiabilidade pelo alfa de Crombach, eventualmente corrigindo-a;

- Passo 3: Categorizar o desempenho e medir os indicadores. O grupo estabelece categorias de desempenho para os indicadores, às quais se associa uma escala conveniente de valores (ótimo $=1$; bom $=0,75$; médio $=0,5$; ruim $=0,25$; e péssimo $=0$ ) que os mensurem. Alguns valores de indicadores são obtidos do sistema de informação da empresa. Outros, tais como o valor esperado e a variabilidade de tempos de atravessamento e inventário, requerem modelos específicos de cálculo. Por soma de produtos da importância relativa do indicador e da faixa de desempenho atual, chega-se ao valor geral de desempenho estratégico, entre 0 e 1 . O complemento é a lacuna estratégica total a preencher pelo plano;

- Passo 4: Exercer o pré-controle do plano. Cada curso de ação é categorizado, pela mesma escala já cita- 


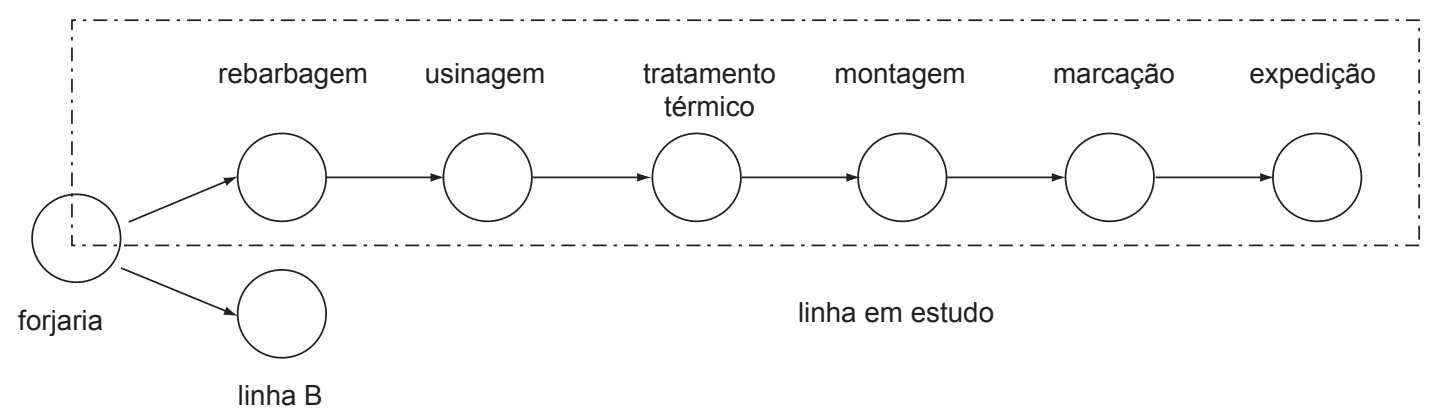

Figura 3. Grafo da manufatura em estudo.

da, quanto à sua capacidade de superar lacunas de indicadores e contribuir para preencher a lacuna total: $($ plena $=1 ;$ forte $=0,75 ;$ média $=0,5 ;$ fraca $=0,25 ;$ e nula =0). Por exemplo, caso o grupo julgue que um dado curso de ação contribua para o preenchimento de toda a lacuna existente entre o objetivo e a situação atual do indicador, categorizará o curso em relação a este indicador como de capacidade plena, atribuindo o valor 1. Por combinação dos julgamentos, o grupo estima o desempenho a que se chegaria com a execução de todos os cursos e, persistindo uma lacuna total, modifica previamente os cursos de ação;

- Passo 5: Priorizar a execução estratégica. Cada curso de ação tem um desencaixe, o valor de recursos financeiros a serem gastos, e um mérito, o percentual da lacuna total que o curso supera. Por um modelo de otimização combinatória, para diversos níveis de restrição de desencaixe, monta-se o plano que alcance o maior preenchimento da lacuna estratégica; e

- Passo 6: Executar e controlar o plano. O último passo é ativar os cursos priorizados, não sendo objetivo desta pesquisa acompanhar o ciclo de controle no tempo. Por este motivo, prefere-se, por ora, falar apenas em précontrole do plano estratégico de manufatura.

\section{Aplicação e resultados}

No passo 1, recuperaram-se os seis objetivos estratégicos atuais e os quinze cursos de ação planejados para atingi-los. Os objetivos são: i) melhorar a resposta dos atuais processos, um objetivo de operação; ii) qualificar colaboradores, um objetivo que se relaciona com a estratégia de recursos humanos; iii) aumentar a carga da fábrica, um objetivo que se relaciona com a estratégia de mercado; iv) reduzir atrasos de fabricação, um objetivo de operação; v) entrar no mercado automobilístico, um objetivo que se relaciona com a estratégia de mercado; e vi) aumentar a eficiência da fábrica, um objetivo de operação. Os cursos de ação são: 1) desgargalamento da fábrica; 2) modificar layout da fábrica; 3 ) introduzir sistema de remuneração variável; 4) treinamento em me- trologia e interpretação de desenho; 5) treinamento em gerência de produção; 6) treinamento sobre os projetos dos produtos; 7) identificar representantes na região norte do Brasil; 8) introduzir programação fina de produção; 9) criar área para estoque de matéria-prima; 10) criar sistema de informação de PCP; 11) implantar norma ISO TS 9000 ; 12) automatizar carga e descarga de máquinas; 13) adquirir equipamentos de transporte interno; 14) adquirir novos equipamentos de produção; e 15) reformar máquinas em mortalidade senil.

Vale salientar que a maior parte das ações se relaciona com operações de manufatura, mas há ações relacionadas com outras estratégias funcionais, tais como ações comerciais e de recursos humanos, sugerindo uma meso-estratégia de gestão de demanda. As ações de manufatura são afetadas pela estratégia funcional de finanças, pois, apesar dos cursos de ação terem viabilidade econômica, pode não ser de interesse alocar neles os recursos disponíveis.

A empresa adota um processo formal de planejamento estratégico, conduzido por executivos do setor de planejamento. No caso, participaram quatro executivos, todos de formação superior, que conduziram o processo de análise de cenário, conexão com a matriz e formulação da estratégia e tomaram as decisões mais relevantes do processo. Por isso, também são chamados de decisores.

No passo 2, um grupo focado formado pelos quatro decisores foi conduzido pelo pesquisador. O grupo explicitou seu entendimento sobre a rota estratégica através da Figura 4, na qual se observam arborescências, indicando eventos que se agregam logicamente, e filas, indicando eventos que contribuem para o objetivo e ocorrem em momentos diferentes e em seqüência.

Para atingir o primeiro objetivo, os decisores entendem que se deve melhorar três construtos: a exigência dos recursos produtivos, a manutenção e a qualidade. A exigência diz respeito ao esforço da manufatura e é maior quanto mais complexo for o processo de fabricação e pode ser apreendida pelo tempo-padrão do principal produto. A manutenção é melhor quanto menos quebras houver e mais rápidas forem sanadas e pode ser apreendida pela 


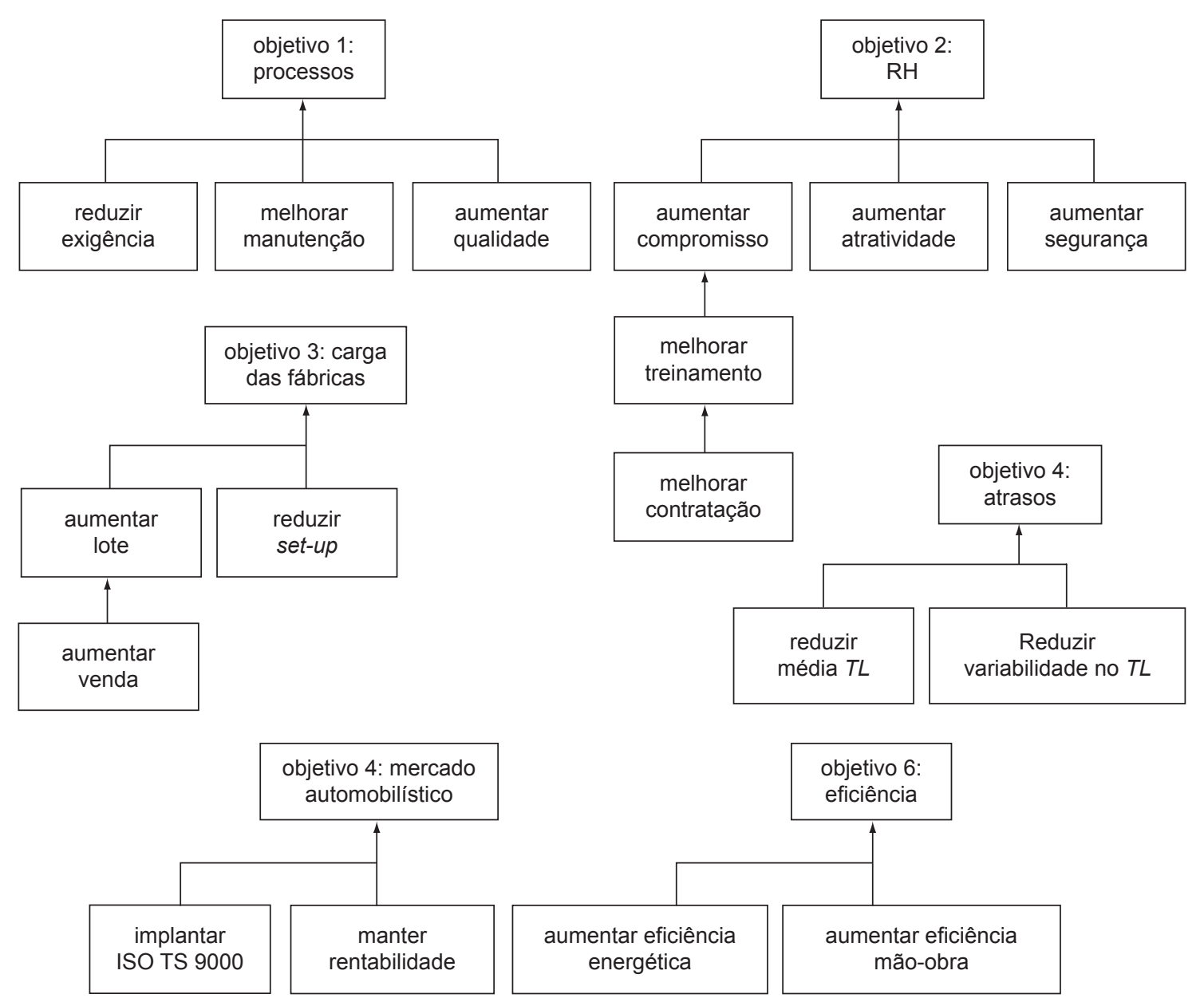

Figura 4. Representação da rota estratégica.

menor disponibilidade entre as máquinas gargalo. A disponibilidade considera os tempos médios entre quebras, o $M T B F$, e entre reparos, o MTTR, que exigem modelos probabilísticos e é dada pela Equação 1. Finalmente, o construto qualidade pressupõe os conceitos de capabilidade de processo e da necessidade de se fazer uma tarefa corretamente pela primeira vez, sendo seu complemento apreendido pelos percentuais de refugo e retrabalho.

$$
A_{v}=\min \left[\frac{M T B F}{M T B F+M T T R}\right]
$$

O segundo objetivo é qualificar os recursos humanos. A estratégia se compõe de três construtos, a qualificação intrínseca de operadores, a segurança no trabalho e a atratividade do trabalho, apreendidos pelos conceitos de contratação, treinamento, compromisso com a tarefa, afastamento por acidentes e rotatividade. A qualificação é sustentada por uma estrutura em fila, não necessariamente com relações de causalidade. Por exemplo, a correta contratação é um antecedente, mas não é uma causa de um bom treinamento, que por sua vez antecede, mas não causa o compromisso com a tarefa.
O terceiro objetivo, aumentar a carga da fábrica, pode ser atingido por dois construtos, o aumento da produção e o aumento da produtividade. Os construtos são sustentados por aumento de vendas, redução nas interrupções, redução do tempo de set-up e pela redução das faltas de materiais em meio às ordens, o que força set-ups extras. O construto é apreendido pelos indicadores ritmo de produção e \% tempo de set-up, antecipados pelos indicadores tamanho do mix-padrão e \% de OF cumpridas sem interrupção. O mix-padrão é o conjunto de produtos de maior venda e que são produzidos para estoque, pois se acredita que a venda sempre ocorrerá. Os itens fora do mix-padrão só são fabricados se houver um pedido firme.

O quarto objetivo é reduzir o tempo de execução de ordens. Como a manufatura é um sistema de filas, o tempo até a conclusão da ordem (TL) é influenciado pelo valor esperado e pela variabilidade do tempo de execução e são antecipados por indicadores de inventário.

O quinto objetivo é entrar e se manter no mercado automobilístico. Para tal, assume-se o pressuposto de que é necessária a adoção da norma ISO TS, porém sem perda 
de rentabilidade. O objetivo é medido pelo \% de vendas no setor, antecipado pelo \% de implantação da norma. A condição necessária é medida pela rentabilidade das ordens entregues no setor. Após se formar um histórico, por regressão, poder-se-á verificar se a implantação da norma realmente abriu o mercado automobilístico para a manufatura, ou se outra premissa deve ser adotada.

O sexto objetivo é aumentar a eficiência da manufatura, medida pelo uso dos dois recursos variáveis mais relevantes, os recursos humanos e a energia elétrica. Os consumos específicos faturados são antecipados pelos consumos específicos produzidos.

Usando o método AHP de apoio à decisão multicriterial, o grupo chegou à estrutura arborescente ponderada da Tabela 2. A primeira camada foi julgada em conjunto, resultando nas importâncias relativas da primeira coluna. Os decisores preferiram julgar individualmente a segunda camada, o que gerou as médias e variabilidades da terceira e da quarta coluna. Nas últimas colunas têm-se as importâncias relativas finais, obtidas pela multiplicação da média da importância relativa do indicador pela importância relativa do objetivo e as ordens de importância dos indicadores, segundo os decisores.

Para verificar a confiabilidade da estrutura de medição, os decisores avaliaram a realidade dos conceitos intangíveis que expressam as idéias aglutinadas nos indicadores, chegando a um alfa de Crombach de 0,91. Hair et al. (1998) apontam valores de alfa maiores que 0,55 como aceitáveis, logo o teste aceita a estrutura de medição proposta.

No passo 3, o grupo estipulou as faixas de desempenho da Tabela 3, que também apresenta a medição atual. A situação atual de cada indicador foi mensurada e categorizada, resultando um desempenho total próximo a $49 \%$ dos objetivos estratégicos. Na Tabela 4, são apresentados os objetivos e os respectivos indicadores, a importância relativa de cada indicador para o desempenho global, o desempenho de cada indicador, as lacunas de

Tabela 2. Estrutura da estratégia incremental de manufatura.

\begin{tabular}{|c|c|c|c|c|c|}
\hline \multirow{2}{*}{$\begin{array}{c}\text { Objetivos estratégicos } \\
\text { e importâncias }\end{array}$} & \multirow[t]{2}{*}{ Indicadores } & \multicolumn{2}{|c|}{ Importâncias } & \multicolumn{2}{|c|}{ Importância relativa } \\
\hline & & média & cv & valor $(\%)$ & ordem \\
\hline \multirow{4}{*}{$\begin{array}{l}\text { Melhorar a resposta } \\
\text { dos atuais processos } \\
39 \%\end{array}$} & Tempos-padrão de produtos & 0,56 & 0,01 & 21,7 & 1 \\
\hline & Disponibilidade de processos & 0,27 & 0,02 & 10,3 & 3 \\
\hline & Refugo & 0,11 & 0,11 & 4,2 & 8 \\
\hline & Retrabalho & 0,06 & 0,12 & 2,4 & 11 \\
\hline \multirow{5}{*}{$\begin{array}{l}\text { Qualificar } \\
\text { colaboradores } 12 \%\end{array}$} & \% cumprimento requisitos na contratação & 0,50 & 0,04 & 5,9 & 6 \\
\hline & Tempo treinamento & 0,25 & 0,07 & 2,9 & 9 \\
\hline & Absenteísmo & 0,11 & 0,17 & 1,3 & 17 \\
\hline & $\%$ horas de afastamento por acidentes & 0,05 & 0,19 & 0,6 & 22 \\
\hline & Rotatividade & 0,09 & 0,19 & 1,0 & 19 \\
\hline \multirow{5}{*}{$\begin{array}{l}\text { Aumentar a carga } \\
\text { da fábrica } 5 \%\end{array}$} & Unidades vendidas & 0,06 & 0,19 & 0,3 & 25 \\
\hline & $\%$ Tempo de set-up & 0,16 & 0,08 & 0,7 & 21 \\
\hline & Tamanho do mix-padrão & 0,07 & 0,14 & 0,3 & 24 \\
\hline & $\%$ de OF cumpridas sem interrupção & 0,44 & 0,03 & 2,1 & 14 \\
\hline & Ritmo de atendimento a ordens & 0,27 & 0,04 & 1,3 & 18 \\
\hline \multirow{4}{*}{$\begin{array}{l}\text { Reduzir atrasos em } \\
\text { ordens de fabricação } \\
25 \%\end{array}$} & Tempo de atravessamento médio de ordens & 0,53 & 0,06 & 14,0 & 2 \\
\hline & Variabilidade no t. atravessamento de ordens & 0,26 & 0,02 & 6,5 & 5 \\
\hline & Inventário médio & 0,14 & 0,16 & 2,9 & 10 \\
\hline & Desempenho médio & 0,07 & 0,17 & 1,4 & 15 \\
\hline \multirow{3}{*}{$\begin{array}{l}\text { Entrar no mercado } \\
\text { automobilístico 3\% }\end{array}$} & $\%$ de vendas automobilístico em unidades & 0,24 & 0,08 & 0,8 & 20 \\
\hline & $\%$ de vendas no setor automobilístico em $\$$ & 0,66 & 0,03 & 2,1 & 13 \\
\hline & \% de implantação da ISO TS & 0,10 & 0,07 & 0,3 & 23 \\
\hline \multirow{4}{*}{$\begin{array}{l}\text { Tornar equipamentos } \\
\text { mais eficientes } 17 \%\end{array}$} & KWh/unidade produzida & 0,26 & 0,07 & 4,4 & 7 \\
\hline & $\mathrm{KWh} / \$$ faturado & 0,54 & 0,03 & 9,2 & 4 \\
\hline & H.H/unidade produzida & 0,08 & 0,19 & 1,4 & 16 \\
\hline & H.H/\$ faturado & 0,12 & 0,08 & 2,1 & 12 \\
\hline Total $=100 \%$ & & & & Total $=100 \%$ & \\
\hline
\end{tabular}




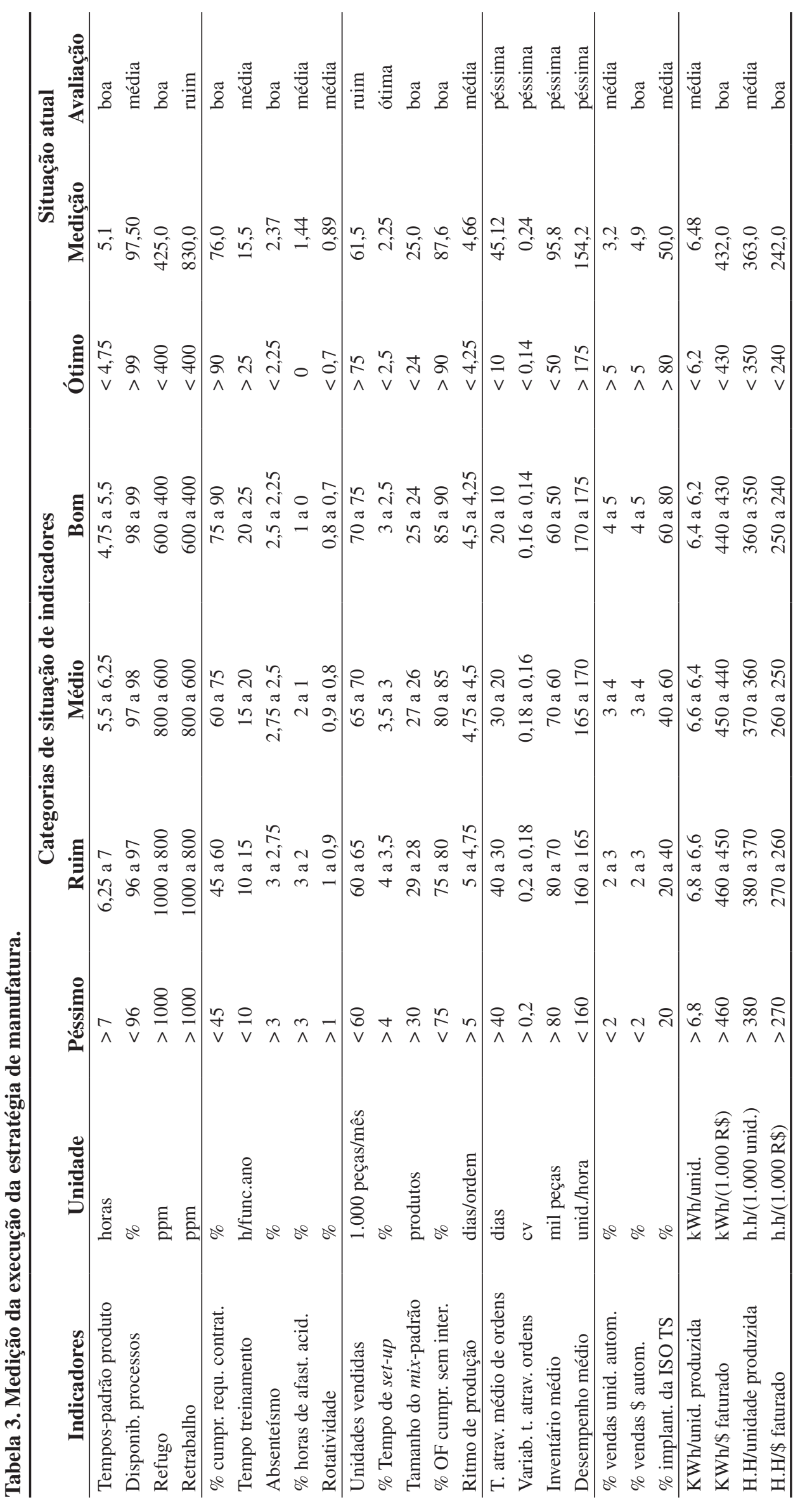


Tabela 4. Desvios na estratégia de manufatura.

\begin{tabular}{|c|c|c|c|c|c|}
\hline & Indicadores & $\begin{array}{l}\text { Importância } \\
\text { relativa }(\%)\end{array}$ & Desempenho (pp) & $\begin{array}{c}\text { Lacuna de } \\
\text { desempenho }(p p)\end{array}$ & Ordem \\
\hline \multirow[t]{4}{*}{ Objetivo 1} & Tempos-padrão produto & 21,72 & 16,29 & 5,43 & 3 \\
\hline & Disponibilidade processos & 10,31 & 5,15 & 5,15 & 4 \\
\hline & Refugo & 4,17 & 3,13 & 1,04 & 12 \\
\hline & Retrabalho & 2,38 & 0,59 & 1,78 & 8 \\
\hline \multirow[t]{5}{*}{ Objetivo 2} & $\%$ cumpr. requisitos contr. & 5,88 & 4,41 & 1,47 & 10 \\
\hline & Tempo treinamento & 2,94 & 1,47 & 1,47 & 11 \\
\hline & Absenteísmo & 1,30 & 0,97 & 0,32 & 20 \\
\hline & $\%$ horas de afast. acidentes & 0,65 & 0,32 & 0,32 & 21 \\
\hline & Rotatividade & 1,01 & 0,51 & 0,51 & 18 \\
\hline \multirow[t]{5}{*}{ Objetivo 3} & Unidades vendidas & 0,27 & 0,07 & 0,20 & 22 \\
\hline & $\%$ tempo de set-up & 0,72 & 0,72 & 0,00 & 25 \\
\hline & Tamanho do mix-padrão & 0,31 & 0,23 & 0,08 & 24 \\
\hline & $\%$ de OP cumpr. sem inter. & 2,05 & 1,54 & 0,51 & 17 \\
\hline & Ritmo de produção & 1,26 & 0,63 & 0,63 & 14 \\
\hline \multirow[t]{4}{*}{ Objetivo 4} & T. atrav. médio de ordens & 13,24 & 0,00 & 13,24 & 1 \\
\hline & Variab. no t. atrav. ordens & 6,44 & 0,00 & 6,44 & 2 \\
\hline & Inventário médio & 3,44 & 0,00 & 3,44 & 5 \\
\hline & Desempenho médio & 1,65 & 0,00 & 1,65 & 9 \\
\hline \multirow[t]{3}{*}{ Objetivo 5} & $\%$ de vendas unid. autom. & 0,77 & 0,39 & 0,39 & 19 \\
\hline & $\%$ de vendas $\$$ autom. & 2,09 & 1,57 & 0,52 & 16 \\
\hline & \% implantação da ISO TS & 0,32 & 0,16 & 0,16 & 23 \\
\hline \multirow[t]{5}{*}{ Objetivo 6} & KWh/unid. produzida & 4,36 & 2,18 & 2,18 & 7 \\
\hline & KWh/\$ Faturado & 9,24 & 6,93 & 2,31 & 6 \\
\hline & H.H/unidade produzida & 1,35 & 0,68 & 0,68 & 13 \\
\hline & H.H/\$ Faturado & 2,13 & 1,60 & 0,53 & 15 \\
\hline & Total & 100 & 49,53 & 50,47 & \\
\hline
\end{tabular}

desempenho de cada indicador, obtidas diminuindo o desempenho da importância relativa, em pontos percentuais (pp) e, na última coluna, a importância estratégica do indicador, ordenados segundo as lacunas de desempenho de posicionamento. Os valores absolutos dos indicadores são obtidos do sistema de informações da empresa. $\mathrm{O}$ modelo probabilístico usado para o cálculo dos indicadores do objetivo 4 é apresentado em Sellitto (2005).

No passo 4, faz-se o pré-controle das ações estratégicas. O grupo categorizou a capacidade dos cursos de ação em superar as lacunas de cada indicador como $($ nula $=0 \%$, fraca $=25 \%$; média $=50 \%$; forte $=75 \%$; e plena $=100 \%$ ). As avaliações, os méritos e os desencaixes são apresentados nas Tabelas 5 e 6 . O mérito de um curso de ação é a soma dos produtos das lacunas de indicadores pelas capacidades de superação destas lacunas, ou o quanto o curso eleva o desempenho global, em pontos percentuais (pp). O desencaixe considera os investimentos materiais e com pessoal. Pela análise dos decisores, o plano acrescenta 38,6 pp aos atuais 49,5 pp, pré-alimentando um desempenho para a estratégia incremental de $88,1 \%$.
Faz-se o pré-controle do plano modificando os cursos de ação já propostos e acrescentando ou retirando cursos de ação do plano.

No primeiro objetivo, a lacuna de desempenho do indicador de refugo é parcialmente preenchida pelo plano. Entende-se que o curso de ação 14 deva incluir um estudo prévio de capabilidade, o que garantiria plenamente a superação da lacuna. Quanto à disponibilidade, o curso de ação 15 prevê reformas em máquinas de alto custo de manutenção, mas com redundância operacional, pois várias máquinas cumprem a mesma tarefa. O curso reduzirá o custo da manufatura, mas não aumentará a disponibilidade, o que interessa à estratégia de finanças, mas não à estratégia de manufatura. Um novo curso deve incluir práticas de manutenção preventiva e preditiva e a compra de peças reservas para máquinas críticas.

No segundo objetivo, as lacunas de desempenho nos indicadores de treinamento e de absenteísmo podem ser preenchidas pela inclusão de um módulo comportamental, pois o treinamento previsto é exclusivamente técnico. As lacunas de desempenho nos indicadores de contratação e de segurança devem ser endereçadas por novos 
Tabela 5. Capacidades dos cursos de ação, $1^{\text {a }}$ parte.

\begin{tabular}{|c|c|c|c|c|c|c|c|c|c|}
\hline \multirow[t]{2}{*}{ Indicadores dos objetivos } & \multicolumn{9}{|c|}{ Capacidade de superação das lacunas dos indicadores } \\
\hline & 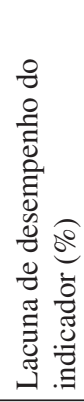 & 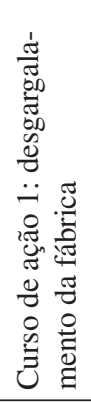 & 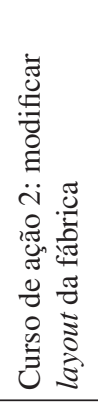 & 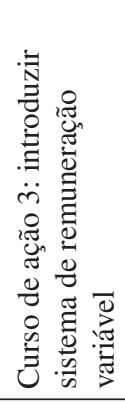 & 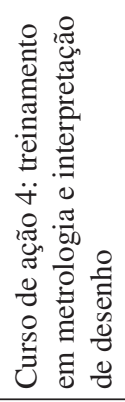 & 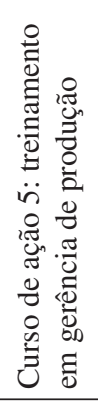 & 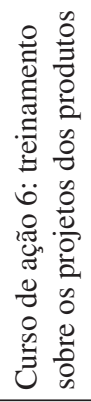 & 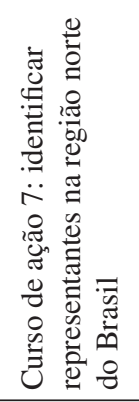 & 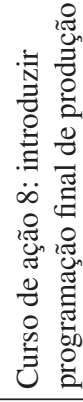 \\
\hline Obj. 1: Tempos-padrão produto & 5,43 & 0,25 & - & - & - & - & 0,25 & - & - \\
\hline Disponibilidade processos & 5,15 & - & - & - & - & - & - & - & - \\
\hline Refugo & 1,04 & - & - & - & 0,25 & - & 0,25 & - & - \\
\hline Retrabalho & 1,78 & - & - & - & 0,25 & - & 0,25 & - & - \\
\hline Obj. 2: \% cumpr. requ. contrat. & 1,47 & - & - & - & - & - & - & - & - \\
\hline Tempo treinamento & 1,47 & - & - & - & 0,5 & 0,25 & - & - & - \\
\hline Absenteísmo & 0,32 & - & - & 0,75 & - & - & - & - & - \\
\hline$\%$ horas afastamento acidentes & 0,32 & - & - & - & - & - & - & - & - \\
\hline Rotatividade & 0,51 & - & - & 1 & - & - & - & - & - \\
\hline Obj. 3: Unidades vendidas & 0,20 & - & - & - & - & - & - & 0,25 & - \\
\hline$\%$ tempo de set-up & 0,00 & 0,25 & - & - & - & 0,25 & - & - & 0,25 \\
\hline Tamanho do mix-padrão & 0,08 & 0,25 & - & - & - & 0,25 & - & - & 0,5 \\
\hline$\%$ OF cumpridas s/ interrupção & 0,51 & 0,25 & 0,25 & - & - & - & - & - & - \\
\hline Ritmo de produção & 0,63 & 0,5 & 0,25 & - & - & - & - & - & - \\
\hline Obj. 4: T. atr. médio de ordens & 13,2 & 0,25 & 0,25 & - & - & - & - & - & 0,25 \\
\hline Variab. no t.atrav. ordens & 6,44 & 0,25 & 0,25 & - & - & - & - & - & 0,25 \\
\hline Inventário médio & 3,44 & 0,25 & 0,25 & - & - & - & - & - & 0,25 \\
\hline Desempenho médio & 1,65 & 0,25 & 0,25 & - & - & - & - & - & 0,25 \\
\hline Obj. 5: $\%$ vendas unid. autom. & 0,39 & - & - & - & - & - & - & - & - \\
\hline$\%$ de vendas $\$$ autom. & 0,52 & - & - & - & - & - & - & - & - \\
\hline \% implantação da ISO TS & 0,16 & - & - & - & - & - & - & - & - \\
\hline Obj. 6: $\mathrm{kWh} /$ unid. produzida & 2,18 & - & - & - & - & - & - & - & - \\
\hline $\mathrm{kWh} / \$$ faturado & 2,31 & - & - & - & - & - & - & - & - \\
\hline H.H/unidade produzida & 0,68 & - & 0,25 & - & - & - & - & - & - \\
\hline H.H/\$ faturado & 0,53 & - & 0,25 & - & - & - & - & - & - \\
\hline Mérito do curso de ação (pp) & & 8,01 & 6,78 & 0,75 & 1,44 & 0,39 & 2,06 & 0,05 & 6,23 \\
\hline Desencaixe (1.000 R \$) & & 160 & 20 & 300 & 30 & 20 & 10 & 120 & 200 \\
\hline
\end{tabular}

cursos de ação, tais como auditoria na contratação e, por meio da CIPA, um programa de prevenção de riscos e de desenvolvimento da saúde ocupacional.

No terceiro objetivo, a lacuna de desempenho no indicador de vendas está sendo preenchida pela entrada no mercado automobilístico e pela nomeação de representantes na região norte do Brasil. Entende-se que o curso deve incluir uma ação mercadológica na região sudeste, pois lá se encontra o maior mercado da empresa, apenas parcialmente explorado.

O quarto e quinto objetivos vão estar sendo totalmente atendidos pelo plano.
No sexto objetivo, para influenciar as lacunas de desempenho nos indicadores de eficiência energética, propõe-se um novo curso de ação específico para conservação de energia. Propõe-se a criação da CICE, a Comissão Interna de Conservação de Energia, que, como na CIPA, deve discutir alternativas para a redução do consumo energético.

As correções aproximam a pré-alimentação do desempenho do plano dos $100 \%$.

No passo 5, priorizam-se os cursos de ação, segundo os seus méritos e restringidos pelo desencaixe total. Será usado um modelo de programação binária em que 
Tabela 6. Capacidades dos cursos de ação, $2^{\mathrm{a}}$ parte.

Indicadores dos objetivos

Capacidade de superação das lacunas dos indicadores

\begin{tabular}{|c|c|c|c|c|c|c|c|c|c|}
\hline & 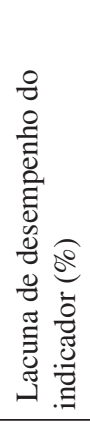 & 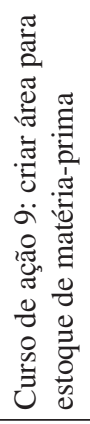 & 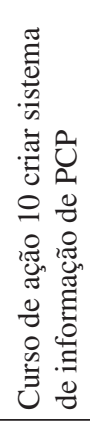 & 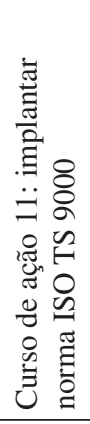 & 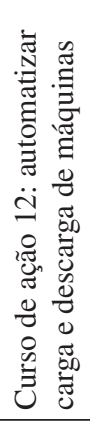 & 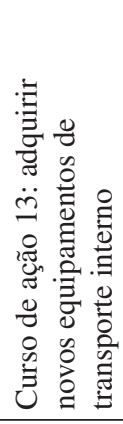 & 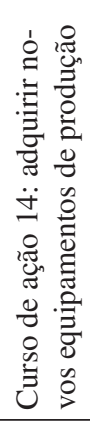 & 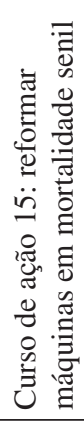 & 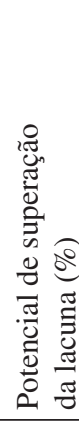 \\
\hline Obj. 1: Tempos-padrão produto & 5,43 & - & - & - & - & - & - & - & 50 \\
\hline Disponibilidade processos & 5,15 & - & - & - & - & - & 0,25 & - & 25 \\
\hline Refugo & 1,04 & - & - & - & - & - & 0,25 & - & 75 \\
\hline Retrabalho & 1,78 & - & - & - & - & - & 0,25 & - & 75 \\
\hline Obj. 2: \% cumpr. requ. contrat. & 1,47 & - & - & - & - & - & - & - & 0 \\
\hline Tempo treinamento & 1,47 & - & - & - & - & - & - & - & 75 \\
\hline Absenteísmo & 0,32 & - & - & - & - & - & - & - & 75 \\
\hline$\%$ horas afastamento acidentes & 0,32 & - & - & - & 0,25 & 0,25 & - & - & 50 \\
\hline Rotatividade & 0,51 & - & - & - & - & - & - & - & 100 \\
\hline Obj. 3: Unidades vendidas & 0,20 & - & - & 0,25 & - & - & - & - & 50 \\
\hline$\%$ tempo de set-up & 0,00 & - & - & - & - & - & - & - & 75 \\
\hline Tamanho do mix-padrão & 0,08 & - & - & - & - & - & - & - & 100 \\
\hline \% OF cumpridas s/ interrupção & 0,51 & 0,25 & - & - & - & - & - & - & 75 \\
\hline Ritmo de produção & 0,63 & - & - & - & 0,25 & - & - & - & 100 \\
\hline Obj. 4: T. atr. médio de ordens & 13,2 & 0,25 & - & - & - & - & - & - & 100 \\
\hline Variab. no t.atrav. ordens & 6,44 & 0,25 & - & - & - & - & - & - & 100 \\
\hline Inventário médio & 3,44 & 0,25 & - & - & - & - & - & - & 100 \\
\hline Desempenho médio & 1,65 & 0,25 & - & - & - & - & - & - & 100 \\
\hline Obj. 5: \% vendas unid. autom. & 0,39 & - & - & 1 & - & - & - & - & 100 \\
\hline$\%$ de vendas $\$$ autom. & 0,52 & - & - & 1 & - & - & - & - & 100 \\
\hline \% implantação da ISO TS & 0,16 & - & - & 1 & - & - & - & - & 100 \\
\hline Obj. 6: kWh/unid. produzida & 2,18 & - & - & - & - & - & 0,5 & - & 50 \\
\hline $\mathrm{kWh} / \$$ faturado & 2,31 & - & - & - & - & - & 0,5 & - & 50 \\
\hline H.H/unidade produzida & 0,68 & - & 0,25 & - & 0,25 & - & 0,25 & - & 100 \\
\hline H.H/\$ faturado & 0,53 & - & 0,25 & - & 0,25 & - & 0,25 & - & 100 \\
\hline Mérito do curso de ação (pp) & & 6,23 & 0,30 & 1,12 & 0,54 & 0,08 & 4,54 & 0,00 & 38,6 \\
\hline Desencaixe (1.000 R\$) & & 40 & 50 & 50 & 200 & 40 & 500 & 80 & \\
\hline
\end{tabular}

cada curso de ação ou entra totalmente ou sai totalmente da solução. Outros modelos podem ser desenvolvidos. A programação linear aceitaria a execução proporcional de cursos de ação. A programação inteira aceitaria a múltipla execução de cursos de ação elementares. And-or graphs são usados, caso se dividam os cursos de ação em subcursos de execução condicional, formando uma rede lógica. O modelo usado utilizou o comando solver do software Excel $^{\circledR}$.

Inicia-se com uma restrição de desencaixe total, relaxando-se, a seguir, a restrição até que todos os cursos de ação tenham emergido, formando uma ordem de prio- ridade. O modelo de programação binária é dado pelas Equações 2 e 3 . A Equação 2 otimiza a seleção dos cursos de ação, maximizando a superação das lacunas de desempenho, enquanto que a Equação 3 representa a restrição aos desencaixes esperados dos cursos de ação.

$$
\max \sum_{i=1}^{15} X_{i \cdot}\left[\sum_{j=1}^{25} V_{i j} \cdot I R_{j}\right]
$$

sujeito à:

$\sum_{i=1}^{15} X_{i} \cdot b_{i} \leq B$, restrição de desencaixe 
nas quais:

- $X_{i} \in[1,0]$, representando se o curso de ação $i$ será ou não realizado;

- $V_{i j} \in[1,0,75,0,5,0,25,0]$, representando a capacidade de superação de lacuna atribuída ao curso de ação $i$ em relação ao indicador $j$;

- $I R_{j}=$ importância relativa do indicador $j, j$ variando de 1 a 25 ; e

- $b_{i}=$ desencaixe do curso de ação $i, i$ variando de 1 a 15.

Na Tabela 7 apresentam-se os resultados da otimização. Observa-se o nível de relaxação da restrição, variando entre $10 \%$ e $90 \%$ do custo da escolha, a resposta da função-objetivo e o teor da escolha. Chama a atenção o fato de, com apenas $30 \%$ de custo, a função-objetivo já ter atingido mais de $85 \%$ do seu valor máximo.

$\mathrm{O}$ passo 6 materializar-se-á à medida que os planos sejam executados e haja ciclos de medição e controle. Como não faz parte do escopo de pesquisa o acompanhamento longitudinal da execução do plano estratégico, limita-se a análise ao pré-controle. Em um projeto de pesquisa que acompanhe os ciclos da execução estratégica, será possível estabelecer continuamente correções nos cursos de ação previstos, pois os principais campos de força que interferem na estratégia estão mapeados e sua intensidade é conhecida.

\section{Uso dos resultados em uma eventual reformulação estratégica}

O caso oferece oportunidades para discussão, que são exploradas em Sellitto (2005). Por ora, dá-se mais ênfase ao resultado a que se chegou e possíveis usos em uma eventual reformulação do plano estratégico ou, até mesmo, da estratégia basal.

Do ponto de vista estrutural, o sistema de medição de desempenho se compõe de trinta e dois elementos hierarquizados: o desempenho global, seis desempenhos de objetivos e vinte e cinco indicadores. $\mathrm{O}$ desempenho estratégico inicial é de 49,53\%, o valor pré-alimentado pelo plano é de $88,1 \%$, podendo chegar a $100 \%$ com as correções sugeridas.

Do ponto de vista da estrutura de competitividade, um dos objetivos, reduzir atrasos em ordens de fabricação, compreende variáveis que já se manifestaram no campo de competição, sendo associáveis à noção de realimentação. Outros três objetivos de competição são apriorísticos: melhorar a resposta dos atuais processos; qualificar colaboradores; e tornar equipamentos mais eficientes, sendo associáveis à noção de pré-alimentação. Os outros dois objetivos, aumentar a carga da fábrica e entrar no mercado automobilístico, mesclam os dois tipos de variáveis, pois se valem de preparação e capacitação prévias, aumento no ritmo de produção e certificação na norma ISO TS, para modificar variáveis de campo que decidem a competição, unidades vendidas e presença no setor automobilístico. Uma discussão sobre estrutura de competitividade é encontrada em Ferraz et al. (1996).

Quanto às ações, a execução de oito cursos garante mais de $85 \%$ do resultado total. Em uma análise conjunta com a estratégia funcional de finanças, alguns dos cursos não serão realizados. Em uma análise exclusivamente do ponto de vista da manufatura, o curso de ação 15 não é viável e não deve ser realizado. Conclui-se que os cursos de 1 a 14 são a estratégia pretendida, o curso 15 é a estratégia abandonada e eventuais novos cursos de ação são a estratégia emergente, como preconizado em Mintzberg et al. (2000).

Os resultados atuais combinados dos objetivos funcionais de manufatura podem ser úteis em uma eventual reformulação da estratégia, tanto basal como incremental.

Os resultados atuais dos objetivos são resumidos na Tabela 8, que apresenta as importâncias relativas, os desempenhos absolutos e os desempenhos relativos, os dois últimos em pontos percentuais (pp). Os desempenhos relativos foram obtidos dividindo-se o desempenho absolu-

Tabela 7. Priorização dos cursos de ação.

\begin{tabular}{cccc}
\hline Relaxação $(\boldsymbol{\%})$ & Custo & FO & Cursos de ação escolhidos \\
\hline 10 & 170 & 0,197 & $2 ; 4 ; 5 ; 6 ; 9 ; 11 ;$ \\
20 & 330 & 0,278 & $1 ; 2 ; 4 ; 5 ; 6 ; 9 ; 11 ;$ \\
30 & 530 & 0,340 & $1 ; 2 ; 4 ; 5 ; 6 ; 8 ; 9 ; 11 ;$ \\
40 & 620 & 0,342 & $1 ; 2 ; 4 ; 5 ; 6 ; 8 ; 9 ; 10 ; 11 ; 13 ;$ \\
50 & 880 & 0,349 & $1 ; 2 ; 3 ; 4 ; 5 ; 6 ; 8 ; 9 ; 10 ; 11 ;$ \\
60 & 1.080 & 0,377 & $1 ; 2 ; 4 ; 5 ; 6 ; 8 ; 9 ; 10 ; 11 ; 14 ;$ \\
70 & 1.270 & 0,381 & $1 ; 2 ; 4 ; 5 ; 6 ; 8 ; 9 ; 11 ; 12 ; 13 ; 14 ;$ \\
80 & 1.420 & 0,386 & $1 ; 2 ; 3 ; 4 ; 5 ; 6 ; 8 ; 9 ; 10 ; 11 ; 13 ; 14 ;$ \\
90 & 1.620 & 0,389 & $1 ; 2 ; 3 ; 4 ; 5 ; 6 ; 8 ; 9 ; 10 ; 11 ; 12 ; 13 ; 14 ;$ \\
\hline
\end{tabular}


to pela importância relativa. A situação atual é apresentada na análise bidimensional da Figura 5, cujos limites são fixados a um terço de distância dos eixos e apóiam a análise visual.

Pretende-se que esta análise seja uma variante da apresentada em Slack (1993).

Chama a atenção a posição do objetivo reduzir atrasos de fabricação. A correção desta posição pode exigir decisões basais, tais como passar a produzir internamente insumos críticos, ou decisões incrementais, tais como a duplicação de máquinas ou a modificação do projeto do produto.

Também chama a atenção o acúmulo de objetivos próximos à região de excesso, o que pode apontar para uma má distribuição de recursos, pois parece dar-se mais atenção a objetivos de menor importância, tais como entrar no mercado automobilístico, aumentar a carga da fábrica e qualificar colaboradores, e negligenciar-se um objetivo mais importante, a redução de atrasos.

O objetivo de eficiência parece estar um pouco mais bem atendido e o objetivo mais importante, de processo, aproxima-se da região de excelência, o que pode ser

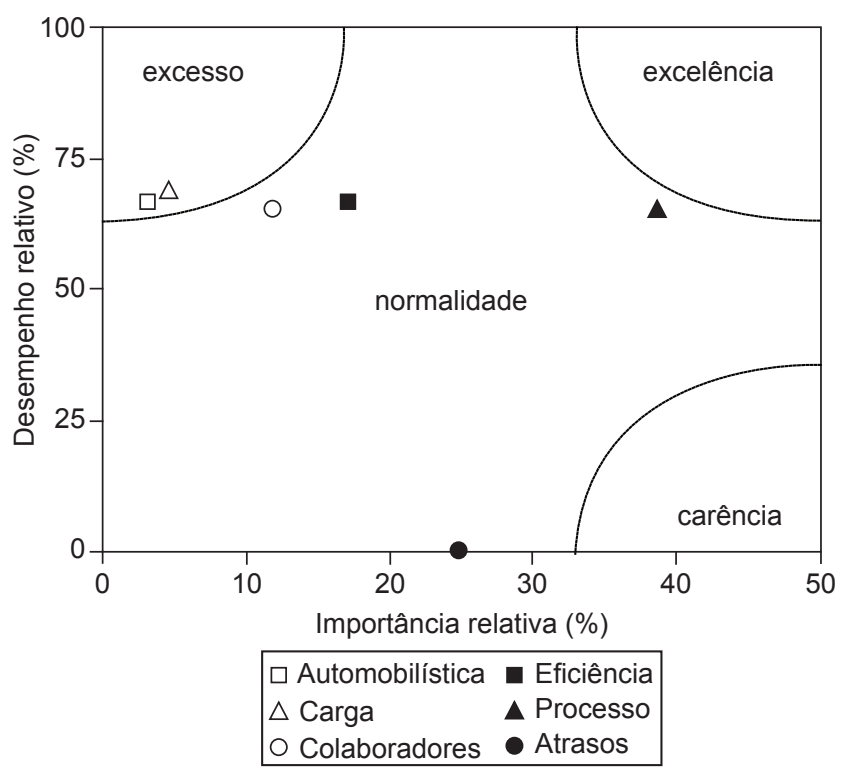

Figura 5. Análise bidimensional da execução estratégica original. uma vantagem de competição. Os decisores, consultados acerca deste resultado, concordaram intuitivamente: o processo tem sido priorizado, atrasos de fabricação têm sido negligenciados e os objetivos de aumento de vendas e entrar no setor automobilístico têm sido privilegiados pela gestão.

Quanto ao método empregado no caso, destaca-se apenas o uso do AHP. O método não admite as ambivalências e ambigüidades admitidas por outros métodos, exigindo que os decisores assumam preferências ou indiferenças entre as alternativas. O método foi facilmente entendido e aplicado pelos decisores, pois destes foi exigido comportamento racional na avaliação das estratégias. Menciona-se um problema metodológico intrínseco ao AHP: os resultados tornaram-se inconsistentes e exigiram a reformulação de um julgamento em que se retirou um indicador. Este efeito é referido em Gomes, Araya e Carignano (2004).

Outros aspectos metodológicos, incluindo o uso de cenários alternativos e famílias de estratégias incrementais, são discutidos em Sellitto (2005).

\section{Considerações finais e continuidade}

O objetivo de pesquisa deste artigo foi propor e testar um método para a medição e o pré-controle do desempenho de um plano estratégico de manufatura. Pelos motivos já mencionados, por ora falou-se apenas em pré-controle. À medida que o desempenho do plano se movimentar e as ações de controle modificarem as intensidades dos cursos em ação, será possível obter uma série histórica do desempenho estratégico de manufatura. Esta série é a representação numérica de um processo evolutivo que interage com o ambiente e tem uma trajetória irreversível no tempo, pois resulta de decisões tomadas em pontos de bifurcação, os cursos de ação, cujas conseqüências são, quase sempre, irreversíveis.

A partir da estratégia de manufatura e de seus objetivos, propôs-se um método para a definição de indicadores e de sua importância relativa. Partindo do desempenho medido pelos indicadores, o método mensurou o potencial de cada ação em contribuir para atingir os objetivos, seguido de uma avaliação das lacunas entre o objetivo de desempenho, o desempenho atual e o desempenho es-

Tabela 8. Resultados dos objetivos estratégicos.

\begin{tabular}{lccc}
\hline Objetivo estratégico & Importância relativa (\%) & Desempenho absoluto (pp) & Desempenho relativo (\%) \\
\hline Obj. 1: Processos & 38,57 & 25,16 & 65,24 \\
Obj. 2: Colaboradores & 11,78 & 7,68 & 65,24 \\
Obj. 3: Carga da fábrica & 4,61 & 3,19 & 69,14 \\
Obj. 4: Atrasos & 24,78 & 0,00 & 0,00 \\
Obj. 5: Automobilístico & 3,18 & 2,11 & 66,46 \\
Obj. 6: Eficiência & 17,08 & 11,38 & 66,65 \\
Soma & 100,00 & 49,53 & \\
\hline
\end{tabular}


perado das ações. Avaliou-se finalmente, em função dos potenciais de melhoria de desempenho de cada ação e das restrições de investimento, a priorização das ações. Também resultaram claras as possíveis alterações no plano estratégico.

Entende-se que se chegou a um sistema de medição de desempenho de um plano de ações estratégicas em manufatura que é compreensivo e flexível em relação aos fatores de competição e aos objetivos da manufatura. Sempre que variar o ambiente de competição, a importância dos objetivos e os próprios objetivos, mediante procedimentos de apoio à decisão em grupo, modificam-se as medições de modo consistente com a estratégia.

Entende-se que se chegou a uma estrutura cibernética, pois há uma variável agregada, o desempenho estratégico global, que realimenta o processo estratégico. Também se entende que se chegou ao formato de sistema aberto, pois as múltiplas variáveis que compõem a realimentação dão origem a múltiplos e diversificados modos de controle, que interagem com o ambiente, inclusive com influências mútuas, como nos cursos de ação que influenciam diversos indicadores.

Manifesta-se, deste modo, a complexidade em manufatura, pois a inexistência de exclusividade nos efeitos dos cursos de ação faz com que surjam mútuas interações entre os fatores estratégicos que formam a competitividade.

$\mathrm{O}$ caso abre alternativas de continuidade. Uma delas é o estudo de um caso longitudinal, que acompanhe o desempenho do plano no tempo e observe nas grandezas de pré-alimentação, erros e realimentação, os comportamentos típicos de sistemas de controle em malha fechada, tais como as aproximações assintóticas, ultrapassagens e oscilações. Quando os campos de força de uma estratégia atuam, a medição de uma variável do desempenho pode se aproximar da meta de modo assintótico, se as forças não são tão intensas; podem ultrapassar a meta, se as forças são mais intensas do que o esperado; e pode oscilar, se a ultrapassagem do desempenho motivar redução nos campos de força, e, conseqüentemente, redução no desempenho.

Outras alternativas são a automatização do método em um sistema de apoio à decisão em grupo e a extensão da abordagem a operações logísticas e arranjos interorganizacionais.

\section{Reconhecimentos}

Deseja-se reconhecer a participação dos engenheiros Tiago Simioni, Jeferson Dominguez e Maurício Griesang Teixeira e da $\operatorname{Prof}^{\mathrm{a}}$. Dr ${ }^{\mathrm{a}}$. Miriam Borchardt em diferentes etapas da pesquisa. Também se deseja reconhecer a importância para os resultados de pesquisa do papel exercido pelo Prof. PhD João Luiz Becker, Prof. Dr. José Luiz Duarte Ribeiro e Prof. Dr. Peter Bent Hansen, membros da banca que julgou a tese de origem deste artigo. Finalmente, agradece-se aos referees anônimos pela contribuição dada à forma final do artigo.

\section{Referências Bibliográficas}

BITITCI, U. Modelling of performance measurement syste$\mathrm{ms}$ in manufacturing enterprises. International Journal of Production Economics, v. 42, p. 137-147, 1995.

BITITCI, U.; SUWIGNJO, P.; CARRIE, A. Strategy management through quantitative modelling of performance measurement systems. International Journal of Production Economics, v. 69, p. 15-22, 2001.

BITITCI, U.; NUDURUPATI, S.; TURNER, T.; CREIGHTON, S. Web enable performance measurements: management implications. International Journal of Operations and Production Management, v. 22, n. 11, p. 1273-1287, 2002.

BOURNE, M.; MILLS, J.; WILCOX, M.; NEELY, A.; PLATTS, K. Designing, implementing and updating performance measurements systems. International Journal of Operations and Production Management, v. 20, n. 7, p.754-771, 2000.

CONTADOR, J. Modelo para aumentar a competitividade industrial. São Paulo: Edgard Blücher, 1996.
DAVIS, M.; AQUILANO, N.; CHASE, R. Fundamentos da administração da produção, Porto Alegre: Bookman, 2001.

EVANS, J. An exploratory study of performance measurement systems and relationships with performance results. Journal of Operations Management, v. 22, p. 219-232, 2004.

FERRAZ, J; KUPFER, D.; HAGUENAUER, L. Made in Brazil: desafios competitivos para a indústria. $\mathrm{R}$. Janeiro: Campus, 1996.

GASPARETTO, V. Proposta de uma sistemática para avaliação de desempenho em cadeias de suprimentos. 2003. 248 p. Tese de doutorado. Engenharia de Produção e Sistemas, UFSC, Florianópolis.

GOMES, C.; YASIM, M.; LISBOA, J. An examination of manufacturing organizations's performance evaluation: analysis, implications and a framework for future research. International Journal of Operations and Production Management, v. 24, n. 5, p. 488-513, 2004. 
GOMES, L; ARAYA, M.; CARIGNANO, C. Tomada de decisões em cenários complexos. São Paulo: Thomson Learning, 2004.

HAIR, J.; TATHAM, R.; ANDERSON, R.; BLACK, W. Multivariate Data Analysis. New Jersey: Prentice Hall, 1998.

HANSEN, P. Um modelo meso-analítico de medição de desempenho competitivo de cadeias produtivas. 2004. 353 p. Tese de doutorado. Escola de Engenharia, UFRGS, Porto Alegre.

HAYES, R.; WHEELWRIGTH, S. Restoring our competitive edge: competing through manufacturing. New York: John Wiley \& Sons, 1984.

KAPLAN, R.; NORTON, D. A estratégia em ação: o Balanced Scorecard. Rio Janeiro: Campus, 1997.

KENNERLY, M.; NEELY, A. Measuring performance in a changing business environment. International Journal of Operations and Production Management, v. 23, n. 2, p. 213-229, 2003.

MARTINS, R. Sistemas de medição de desempenho: um modelo para estruturação do uso. 1998. 248 p. Tese de doutorado. Escola Politécnica, USP, São Paulo.

MELNICK, S.; STEWARD, D.; SWINK, M. Metrics and performance measurements in operations management: dealing with the metrics maze. Journal of Operations Management, v. 22, p. 209-218, 2004.

MINTZBERG, H.; AHLSTRAND, B.; LAMPEL, J. Safári de estratégia: um roteiro pela selva do planejamento estratégico. Porto Alegre: Bookman, 2000.

MIRANDA, L.; SILVA, J. Medição de desempenho. In: SCHMIDT, P (org.). Controladoria: agregando valor para a empresa. Porto Alegre: Bookman, 2002.

MÜLLER, C. Modelo de gestão integrando planejamento estratégico, sistema de avaliação de desempenho e gerenciamento de processo. 2003. 292 p. Tese de douto- rado. Escola de Engenharia, UFRGS, Porto Alegre.

NEELY, A.; GREGORY, M.; PLATTS, K. Performance measurement system design: A literature review and research agenda. International Journal of Operations and Production Management, v. 15, n. 4, p. 80-116, 1995.

PAIVA, E.; CARVALHO, J.; FENSTERSEIFER, J. Estratégia de produção e de operações, Porto Alegre: Bookman, 2004.

PEREIRA, E.; NAGANO, M. Gestão estratégica de custos, In: SCHMIDT, P. (org.) Controladoria: agregando valor para a empresa, Porto Alegre: Bookman, 2002.

ROESCH, S. Projetos de estágio e de pesquisa em administração: guia para estágios, trabalhos de conclusão, dissertações e estudos de caso. São Paulo: Atlas, 1999.

RUSSELL, B. A perspectiva científica. São Paulo: Nacional, 1977.

SELLITTO, M. Medição e controle de desempenho estratégico em sistemas de manufatura. 2005. 195 p. Tese de doutorado. Escola de Engenharia, UFRGS, Porto Alegre.

SKINNER, W. Manufacturing strategy on the "S" curve. Production and operations management, v. 5, n. 1, p. 3-13, 1996.

SLACK, N. Vantagem competitiva em manufatura: atingindo competitividade nas operações industriais. São Paulo: Atlas, 1993.

WHEELWRIGTH, S. Manufacturing strategy: defining the missing link. Strategic Management Journal, v. 5, n. 1, p. 77-91, 1984.

WHITE, G. A survey and taxonomy of strategy-related performance measures for manufacturing. International Journal of Operations and Production Management, v. 16, n. 3, p. 42-61, 1996.

WIENDAHL, H. Betriebs-organisation für ingenieure. Alemanha: Carl Hansen Verlag, 1989. 


\title{
PERFORMANCE MEASUREMENT AND PRECONTROL OF A STRATEGIC MANUFACTURING ACTION PLAN
}

\begin{abstract}
This paper discusses a methodology to measure and precontrol the performance of a strategic manufacturing action plan. A research premise is that the methodology can change measurements as rapidly as modifications in the competitive environment occur, thus keeping the strategy aligned with strategic manufacturing goals. A case study was conducted at a mechanical tools manufacturer to test and refine the method. The company's incremental manufacturing strategy, consisting of six goals and fifteen courses of action, was revamped and a multicriterial approach applied to define indicators and their weights. Based on the current performance measured by the indicators, the method assesses each action's potential to contribute toward achieving the objectives. It then goes on to evaluate the gaps between the performance objectives, current performance and the performance expected to result from those actions, subject to investment constraints. This approach allows for modifications of the strategy, enhancing feedforward performance and characterizing the strategic precontrol action. Some of the results of this case study are discussed, prompting alternatives for continuity.
\end{abstract}

Keywords: manufacturing performance measurement, strategic manufacturing control, manufacturing strategy. 